\title{
Experimental Study on the Feasibility of Using Water Glass and Aluminum Sulfate to Treat Complications in High Liquid Limit Soil Subgrade
}

\author{
Wen-hui Zhang, ${ }^{1,2}$ Hua-wen Zheng, ${ }^{3}$ Jia-wei Qi, ${ }^{1,2}$ and Bao-tian Wang ${ }^{1,2}$ \\ ${ }^{1}$ Key Laboratory of Ministry of Education for Geomechanics and Embankment Engineering, Hohai University, Nanjing 210098, China \\ ${ }^{2}$ Geotechnical Research Institute of Hohai University, Nanjing 210098, China \\ ${ }^{3}$ CCCC Third Harbor Consultants Co., Ltd., Shanghai 200032, China
}

Correspondence should be addressed to Wen-hui Zhang; hhuwenhui@126.com

Received 25 November 2014; Accepted 13 March 2015

Academic Editor: Chi-Wai Chow

Copyright (C) 2015 Wen-hui Zhang et al. This is an open access article distributed under the Creative Commons Attribution License, which permits unrestricted use, distribution, and reproduction in any medium, provided the original work is properly cited.

\begin{abstract}
The feasibility of using water glass and aluminum sulfate to treat high liquid limit soil subgrade diseases is studied through laboratory experiments, and the following results were observed. After improving the high liquid limit clay with water glass and aluminum sulfate, the liquid limit decreases, the plastic limit increases, and the plasticity index decreases. Compared with untreated soil, the clay content of the improved soil decreases, while the silt and coarse contents increase. The absolute and relative expansion rates of the improved soil are both lower than those of the untreated soil. With the same number of dry and wet cycles, the decreased degrees of cohesion and internal friction angle of the improved soil are, respectively, one-half and one-third of those of the untreated soil. After three dry and wet cycles, the California bearing ratio (CBR) of the untreated soil does not meet the requirements of specifications. However, after being cured for seven days and being subjected to three dry and wet cycles, the CBR of the improved soil, with $4 \%$ water glass solution and $0.4 \%$ aluminum sulfate, meets the requirements of specifications.
\end{abstract}

\section{Introduction}

A large amount of high liquid limit soil often appears during the construction of high-grade highways in the central and southwestern regions of China. High liquid limit soil is characterized by a high natural moisture content, high liquid limit, and large fine grain content. When using high liquid soil as subgrade filler, the major engineering issues involved are as follows. The first issue is moisture content control. The natural moisture content of high liquid limit soil is quite high; thus it is difficult to reduce its moisture content to the optimum value. It is also difficult to compact the soil during rolling if the moisture content is too high and when the soil is hard while the moisture content is lower than the plastic limit, thus causing the soil to be difficult to crush $[1,2]$. The second issue is strength. The strength (CBR) of high liquid limit soil is quite low [3]; thus it is generally difficult to meet the requirements of the specifications [4]. The third issue is water stability.
The water stability of high liquid limit soil is rather poor [5]; thus when the highway is in use the soil structure may be gradually destroyed during the alternating dry and wet cycles caused by seasonal climate changes, leading to uneven settlement, subgrade slope collapse, and pavement cracking as well as other complications [6, 7]. In regard to the above issues, specifications for design of highway subgrades are provided as follows: "Fine grained soil with a liquid limit of greater than $50 \%$ and a plasticity index of greater than 26 may not be directly used as subgrade filler. When using the high liquid limit soil in the excavation section to fill the subgrade, high liquid limit soil should be treated" [4].

After Nanyou (Nanning to Youyiguan) Expressway, which is located in the Guangxi Zhuang Autonomous Region, was being opened to traffic for 2 months, longitudinal cracks in its pavement have appeared; the subgrade filler of crack section is high liquid limit soil [7]. After Nanbai (Nanning to Baise) Expressway, which is located in the Guangxi Zhuang 
TABLE 1: Basic physical property indexes of the high liquid limit soil.

\begin{tabular}{|c|c|c|c|c|c|c|}
\hline $\begin{array}{l}\text { Moisture } \\
\text { content } \\
\%\end{array}$ & $\begin{array}{l}\text { Specific } \\
\text { gravity }\end{array}$ & $\begin{array}{l}\text { Liquid limit } \\
\%\end{array}$ & $\begin{array}{c}\text { Plastic limit } \\
\%\end{array}$ & Plasticity index & $\begin{array}{l}\text { Maximum dry } \\
\text { density } \\
\mathrm{g} / \mathrm{cm}^{3}\end{array}$ & $\begin{array}{c}\text { Optimum } \\
\text { moisture } \\
\text { content } \\
\% \\
\end{array}$ \\
\hline 35.4 & 2.74 & 65.6 & 27.7 & 38 & 1.65 & 21.4 \\
\hline
\end{tabular}

Autonomous Region, was being opened to traffic for 2 months, longitudinal cracks and transverse cracks in its pavement and subgrade slide have appeared [7].

Currently, three methods are involved in the use of high liquid limit soil as subgrade filler. The first method is edge covering or core covering treatment [2]. Edge covering treatment refers to the method in which both sides of the subgrade are filled in layers with filling of high strength and good water stability, while the center of the subgrade is filled in layers with high liquid limit soil. Core covering treatment refers to the method in which both sides and the top and bottom of the subgrade are sealed with filling of high strength and good water stability. However, edge and core covering are not able to fundamentally resolve the destruction of soil structure in alternating dry and wet cycles caused by seasonal climate changes. The second method is mixing crushed stone [8] or gravel [9] and other coarse grained soil into the high liquid limit soil which may alter the content of grains in the soil, making coarse grains act as the soil's framework, thus weakening the impact of the fine grained soil on its characteristics and improving the strength and water stability of the high liquid limit soil. The third method is mixing additives into the high liquid limit soil in order to alter the soil's physical and mechanical characteristics. Chemical reaction of the additives with high liquid limit soil may alter the size composition of the high liquid limit soil, reduce its plasticity index, and increase its strength and water stability. Existing research regarding this method shows the following results. After being improved with lime, cement, rice husk ash, and phosphogypsum, the liquid limit and plasticity index of the high liquid limit soil both decrease and the CBR increases dramatically; thus the high liquid limit soil may be used as a subgrade filler for high-grade highways [10-15]. The water stability of the high liquid limit soil also substantially increases after being improved with lime $[13,14,16]$. After being improved with fly ash, the plasticity index of the high liquid limit soil decreases, while the CBR and unconfined compressive strength increase substantially. With the increase in the fly ash content, the maximum dry density of the improved soil gradually decreases, while the optimum moisture content gradually increases [17]. After mixing "Kangnai" stabilizer, "NCS" stabilizer, or other improved materials into high liquid limit soil, no impacts on the liquid limit of high liquid limit soil have been observed, but it has been shown that this may significantly reduce the plasticity index and substantially increase the strength of high liquid limit soil $[18,19]$.

From the above findings, it may be found that the existing research results are for studies concerning the treatment of high liquid limit soil in subgrade filling. However, as for highgrade highways in China which were constructed relatively early, due to the constraints of technical and economic factors, untreated high liquid limit soil is used directly in the subgrade filling of many highways in high liquid limit soil distribution areas, leading to uneven settlement, subgrade slope collapse, pavement cracking, and other complications during the operation of the highways, significantly affecting their use [7]. Based on this phenomenon, this paper explores a type of additives through laboratory experiments, with the aim of providing an additive which is easily soluble in water, has no toxic side effects, and may be added via the grouting method.

\section{Basic Physical Property Indexes of the High Liquid Limit Soil}

The high liquid limit soil samples used in the experiments were obtained from section K156+200 of Nanyou Road (Nanning-Youyiguan Highway) from a sampling depth of $2.0 \mathrm{~m}$. The soil samples are reddish brown in color, and the content of grains less than $0.075 \mathrm{~mm}$ in size is $89.6 \%$. The basic physical property indexes are shown in Table 1.

According to "Test methods of soils for highway engineering (JTG E40-2007)" [20], the test soil is classified as high liquid limit clay.

\section{Selection of Additive}

The first step of the study is to determine a type of additive which is capable of resolving the subgrade complications by means of the grouting method. When selecting the additive consideration should be given to three aspects: first, an ionic active agent should be used, so as to reduce the charge carried on the surface of the soil grains through displacement, thus reducing the hydrophilicity of the soil; second, cementing materials should be used, so as to form a network structure and enhance the bonding among the soil grains; third, the additive should possess a high water stability.

According to the above three points, a combination of sodium silicate and aluminum sulfate was initially selected as the additive. It was found from the results of viscosity ratio experiments that the viscosity of the mixture remains basically unchanged within a period of eight hours and does not coagulate during grouting construction, thus ensuring good liquidity of the slurry and meeting the requirements of grouting construction [21].

The main component of water glass is sodium silicate, the chemical formula of which is $\mathrm{Na}_{2} \mathrm{O} \cdot n \mathrm{SiO}_{2}$, where $n$ 
represents the modulus of water glass. When the modulus is small, solid sodium silicate is soluble in water, and industrial water glass with a modulus of 2.6 and concentration of $3.26 \mathrm{M}$ was selected for use in the experiments. Aluminum sulfate is a white crystal and is easily soluble in water.

Sodium silicate and aluminum sulfate solutions react rapidly, and the reaction equation is as follows:

$$
\begin{aligned}
3 \mathrm{Na}_{2} \mathrm{SiO}_{3}+\mathrm{Al}_{2}\left(\mathrm{SO}_{4}\right)_{3}+6 \mathrm{H}_{2} \mathrm{O} & \\
& =3 \mathrm{Na}_{2} \mathrm{SO}_{4}+2 \mathrm{Al}(\mathrm{OH})_{3} \downarrow+3 \mathrm{H}_{2} \mathrm{SiO}_{3} \downarrow
\end{aligned}
$$

Aluminum hydroxide and gel particles are generated during the reaction of sodium silicate and aluminum sulfate; the gel is wrapping on the surface of the soil grains and filled in the pores among the soil grains. This effect may reunite the tiny soil grains through cementation and cohesion to form aggregates with a large grain size, thereby reducing the hydrophilicity of the high liquid limit soil and improving its water stability. When the solid mass ratio of the sodium silicate and aluminum sulfate is about $5: 1$, this will not only promote the coagulation of the water glass but it will also cause the coagulation to not proceed too quickly [21]. The concentration of the water glass solution used in the experiments is $3.26 \mathrm{M}$; thus the mass ratio of the water glass and aluminum sulfate is determined to be $10: 1$.

\section{Improvement Experiment}

The respective mass ratios of the water glass solution with a concentration of $3.26 \mathrm{M}$ and dry soil are $1 \%, 2 \%, 4 \%, 6 \%$, and $8 \%$ and those of the aluminum sulfate solid and dry soil are $0.1 \%, 0.2 \%, 0.4 \%, 0.6 \%$, and $0.8 \%$. The combinations of the water glass solution and aluminum sulfate are $1 \%+0.1 \%, 2 \%$ $+0.2 \%, 4 \%+0.4 \%, 6 \%+0.6 \%$, and $8 \%+0.8 \%$.

The improvement of the high liquid limit clay involves the following steps: weigh a certain mass of air-dried soil; weigh a certain mass of water glass solution based on the mass ratio of the water glass solution and dry soil, then uniformly spray the water glass solution on the soil sample, and after uniform mixing let it wait for two hours; weigh a certain mass of aluminum sulfate based on the mass ratio of the aluminum sulfate and dry soil, then dissolve it in water (the water control standard states that, after spraying the water glass solution and aluminum sulfate solution on the soil sample, the soil sample moisture content is the moisture content required in the experiments) and uniformly spray the aluminum sulfate solution on the soil sample mixed with water glass, and let the soil sample wait for two hours; in accordance with the designed dry density, fill the soil sample into the test sample using the static pressure method; finally, after curing the sample to the set age, conduct the experiments.

4.1. Liquid and Plastic Limit Experiment. The moisture content of the samples used in the liquid and plastic limit experiment is $30.0 \%$, and the dry density is $1.60 \mathrm{~g} / \mathrm{cm}^{3}$. The experiment was conducted after curing the sample for seven days. The experimental results are shown in Figure 1.

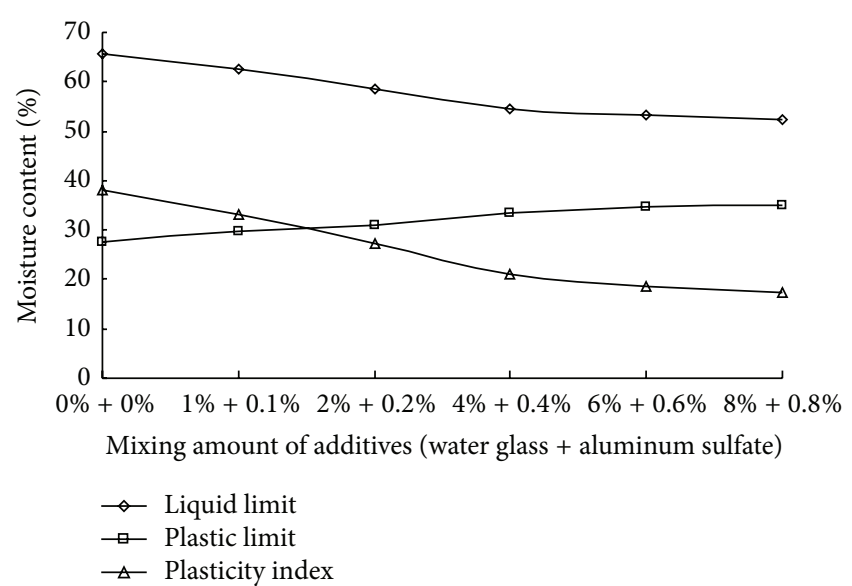

FIGURE 1: Relationship between the limit moisture content and the mixing amount of additives.

As may be seen from Figure 1, after adding the water glass solution and aluminum sulfate solution, the liquid and plastic limits of the high liquid limit clay alter significantly. With the increase in the mixing amount of the water glass and aluminum sulfate solutions, the liquid limit of the improved high liquid limit clay decreases, its plastic limit increases, and its plasticity index decreases. When the mixing amount of the water glass is $4 \%$ and that of the aluminum sulfate is $0.4 \%$, the liquid limit of the improved soil after being cured for seven days is $54.6 \%$ and its plasticity index is 21 , meeting the requirements of the specifications for design of highway subgrades ("Specifications for design," 2004), in which it is stated that the plasticity index of fine grained soil filler must be lower than 26. When the mixing amount of the water glass is $4 \%$ and that of the aluminum sulfate is $0.4 \%$, after continuing to increase the mixing amount of additives, the change range of the plastic limit and plasticity index of the improved soil reduces; thus the mixing amount of the additives is preliminarily determined to be $4 \%$ water glass solution and $0.4 \%$ aluminum sulfate.

The changes in the liquid and plastic limits of the improved high liquid limit clay with $4 \%$ water glass solution and $0.4 \%$ aluminum sulfate with curing age are shown in Figure 2. As may be seen from the figure, the liquid and plastic limits changes of the improved soil were completed seven days after mixing the additives into the high liquid limit clay; after being cured for seven days, the liquid and plastic limits of the improved soil did not show any significant changes with the extension of the curing time.

4.2. Compaction Experiment. The compaction experiment of the improved soil was conducted 12 hours after mixing the additives into the high liquid limit clay, and the experimental results are shown in Figure 3. As may be seen from the figure, the maximum dry density of the improved soil is lower than that of untreated soil, while its optimum moisture content is greater.

4.3. Grain Analysis Experiment. The sample used in the grain analysis experiment of the improved soil with $4 \%$ water glass 


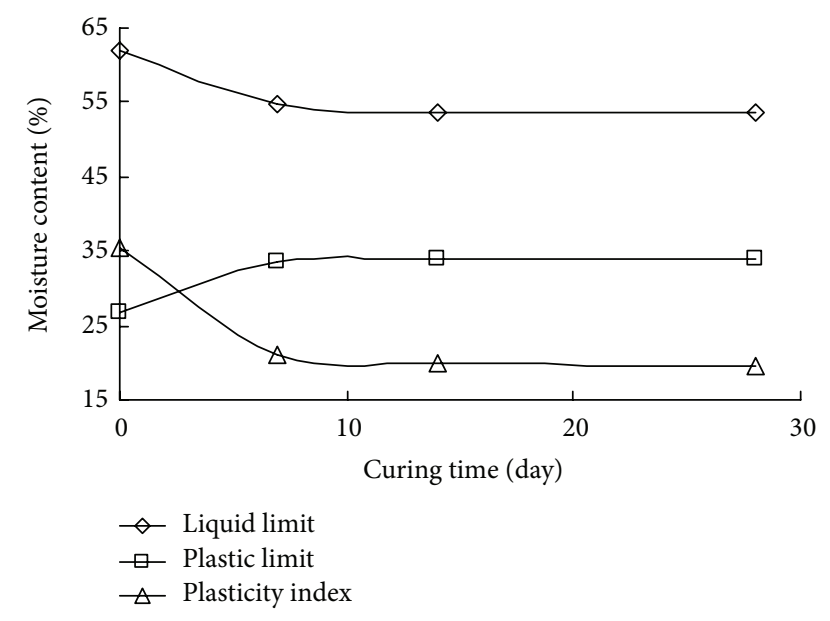

FIgURE 2: Relationship between the limit moisture content of the improved soil and curing time.

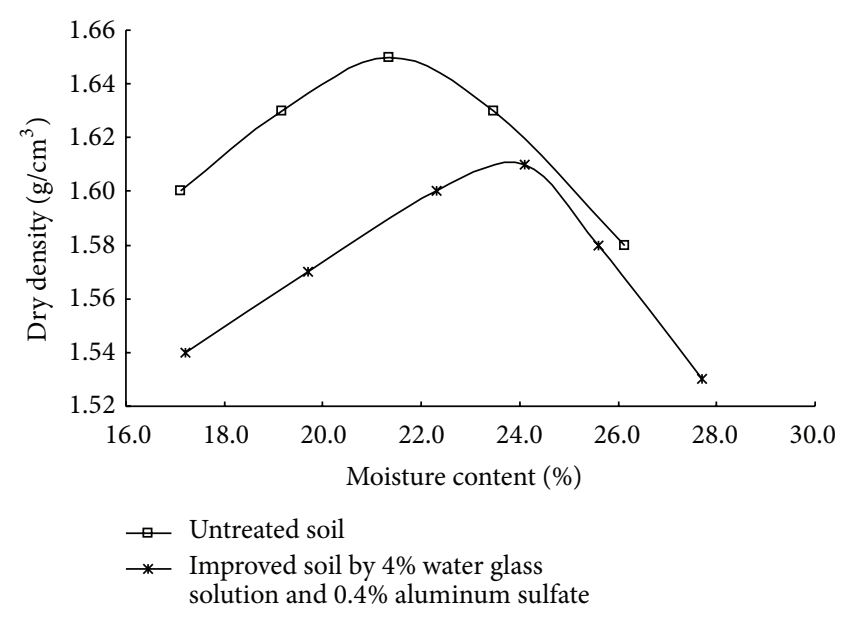

Figure 3: Results of compaction experiment.

solution and $0.4 \%$ aluminum sulfate had a moisture content of $30 \%$ and a dry density of $1.60 \mathrm{~g} / \mathrm{cm}^{3}$. The grain analysis experiment was conducted after curing the sample for seven days. The experimental results are shown in Figure 4, from which the following observations may be made: the content of clay with a grain size less than $0.002 \mathrm{~mm}$ in the untreated soil is $20.8 \%$, while that in the improved soil is $15.6 \%$; the content of silt with grain sizes between 0.002 and $0.075 \mathrm{~mm}$ in the untreated soil is $79.2 \%$, while that in the improved soil is $82.6 \%$; there is no coarse group with a grain size of greater than $0.075 \mathrm{~mm}$ in the untreated soil, while the content of coarse grain group with a grain size of greater than $0.075 \mathrm{~mm}$ is $1.8 \%$ in the improved soil. The experimental results show that, in comparison with the untreated soil, as the contents of the grain groups in the improved soil change, the clay content decreases and the silt and coarse grain contents increase; this is a result of the fact that the gel generated during the reaction of the water glass and aluminum sulfate forms a cohesive layer on the surface of the soil grains, and at the same time the gel

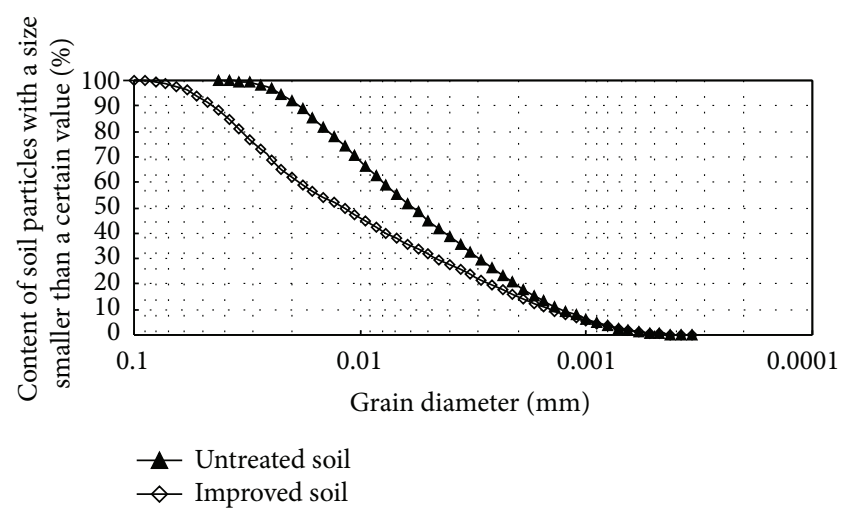

FIGURE 4: Results of the grain analysis experiment.

fills in the pores among the soil grains and promotes their transformation into aggregates.

\section{Water Stability Experiment}

The water stability of the high liquid limit clay and improved soil was studied by means of a dry and wet cycle experiment.

The sample used in the dry and wet cycle experiment had an area of $30 \mathrm{~cm}^{2}$ and a height of $2 \mathrm{~cm}$. The moisture content of the soil sample was mixed to the optimum moisture content, the dry density of the soil sample was $1.54 \mathrm{~g} / \mathrm{cm}^{3}$ (the degree of compaction was $96 \%$ ), and the soil sample was then pressured in the cutting ring with a cross-sectional area of $30 \mathrm{~cm}^{2}$ and a height of $2 \mathrm{~cm}$ via the static pressure method, and the product was used as the test sample.

The dry and wet cycle experiment was divided into the two processes of flooding expansion and dehydration shrinkage. The flooding expansion process was as follows: place the sample on a permeable stone, add water until the water surface and the top surface of the permeable stone are at the same height, have the sample absorb water until it becomes saturated, then gradually raise the water level until the surface of the sample is submerged, and after the sample expansion becomes stable, measure the height of the sample. The dehydration shrinkage process was as follows: dry the saturated sample until its saturation reaches $70 \%$ and then measure the height of the sample.

5.1. Expansion Rate. During the process of the dry and wet cycles, the absolute expansion rate and relative expansion rate were calculated based on the formula below:

$$
\begin{gathered}
\delta_{a}=\frac{h_{i}-h_{0}}{h_{0}}, \\
\delta_{r}=\frac{h_{i}-h_{f(i-1)}}{h_{f(i-1)}},
\end{gathered}
$$

where $\delta_{a}$ and $\delta_{r}$ are the absolute and relative expansion rates, respectively; $h_{i}$ is the height of the sample after the $i$ th expansion becomes stable; $h_{0}$ is the initial height of the sample; and $h_{f(i-1)}$ is the height of the sample after the $(i-1)$ th air drying for the first cycle of dry and wet $h_{f(0)}=h_{0}$. 


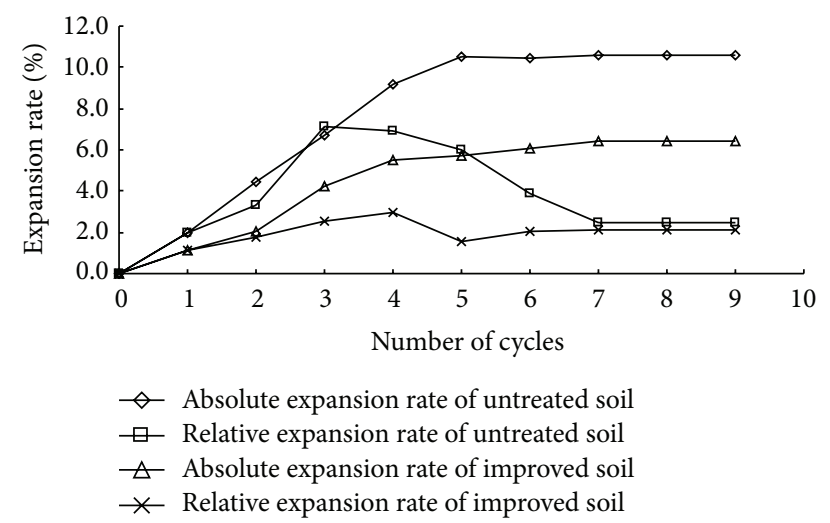

Figure 5: The relationship between the expansion rates and the number of cycles.

The changes in the relationship between the absolute and relative expansion rates of the untreated and improved soils with the number of cycles are shown in Figure 5. As may be seen from the figure, the absolute and relative expansion rates of the improved soil are all lower than those of the untreated soil. The absolute expansion rates of both the untreated and improved soils gradually increase with the increase in the number of dry and wet cycles, and the relative expansion rate remains basically stable after five cycles. The relative expansion rate of the untreated and improved soils first increases and then decreases with the increase in the number of dry and wet cycles, and the relative expansion rate of the untreated soil begins to gradually decrease after the third cycle, while its relative expansion rate begins to stabilize after seven cycles; the relative expansion rate of the improved soil begins to gradually decrease after the fourth cycle, and its relative expansion rate begins to stabilize after six cycles.

5.2. Quick Shear Experiment. The results of the quick shear experiment of the untreated and improved soil samples with $4 \%$ water glass solution and $0.4 \%$ aluminum sulfate after being cured for seven days after different numbers of dry and wet cycles are shown in Figure 6 and Table 2.

As may be seen from Figure 6, the shear strength of the improved soil is higher than that of the untreated soil; the shear strength of the untreated and improved soils gradually decreases with the increase in the number of dry and wet cycles, but the decreased degree gradually reduces with the increase in the number of cycles.

As may be seen from Table 2, the cohesion and internal friction angle of the untreated and improved soils gradually decrease with the increase in the number of dry and wet cycles, but the rate of decrease gradually reduces with the increase in the number of cycles. With the same number of cycles, the cohesion and internal friction angle of the improved soil are larger than those of untreated soil, the reduced degree of cohesion of the improved soil is about onehalf of that of the untreated soil, and the reduced degree of the internal friction angle of the improved soil is about one-third of that of the untreated soil. The above observations show that the water stability of the improved soil is higher than that of

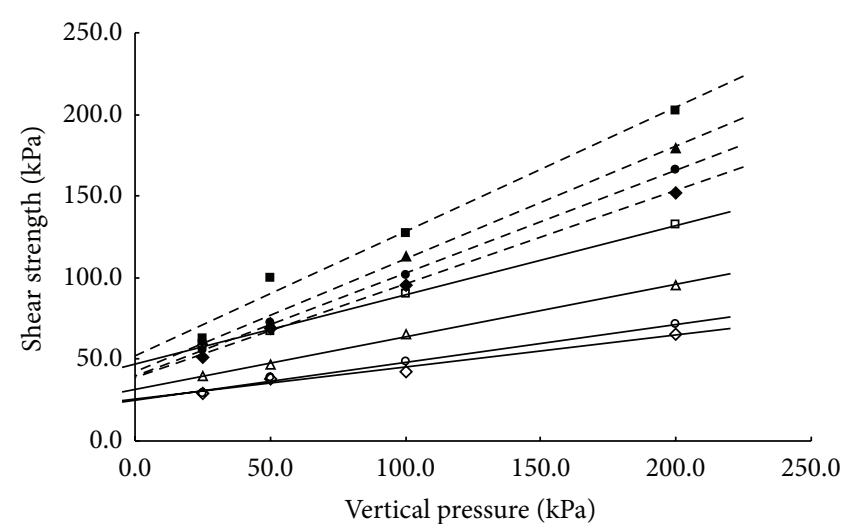

- 0 cycles of improved soil

- 3 cycles of improved soil

- 6 cycles of improved soil

- 9 cycles of improved soil

FIGURE 6: Relationship between shear strength and vertical pressure.

the untreated soil; that is, the water stability of high liquid limit clay significantly increases after being improved with water glass and aluminum sulfate.

5.3. California Bearing Ratio (CBR) Experiment. During the process of three dry and wet cycles, the relative expansion rate of the untreated soil sample reaches its maximum, and the reduced degree of cohesion and internal friction angle are quite high; thus the following comparisons are conducted for the CBR experiment: first, compare the CBR of the untreated soil not being subjected to dry and wet cycles with the CBR of that being subjected to three cycles; second, compare the CBR of the improved soil sample at different curing ages after being subjected to three dry and wet cycles with that of the untreated soil.

The results of the CBR experiments for the untreated and improved soils are shown in Table 3, in which it may be seen that the CBR of the untreated soil sample not subjected to dry and wet cycles is $6.1 \%$, which meets the requirements of the specifications ("Specifications for design," 2004), in which it is stated that subgrade CBR must be greater than $3 \%$. However, the CBR of the untreated soil sample is reduced to $2.7 \%$ after three dry and wet cycles and thus does not meet the requirements of the specifications. The CBR of the improved soil sample with $4 \%$ water glass solution and $0.4 \%$ aluminum sulfate not subjected to dry and wet cycles after being cured for seven days is $18.3 \%$; after being cured for seven days and being subjected to three dry and wet cycles, its CBR is $15.6 \%$, which meets the requirements of the specifications. The CBR of the untreated soil sample after three dry and wet cycles decreases by $55.7 \%$, that of the improved soil sample after being cured for seven days and being subjected to three dry and wet cycles reduces by $14.8 \%$, and that of the improved soil sample after being cured for 28 days and being subjected to three dry and wet cycles reduces by $16.6 \%$; these observations show that the water stability of the improved high liquid limit 
TABLE 2: Results of quick shear experiment.

\begin{tabular}{|c|c|c|c|c|c|}
\hline \multicolumn{2}{|c|}{ Time of dry and wet cycle } & 0 & 3 & 6 & 9 \\
\hline \multirow{2}{*}{$\begin{array}{l}\text { Cohesion } \\
\mathrm{kPa}\end{array}$} & Untreated soil & 47.4 & 31.6 & 25.0 & 23.6 \\
\hline & Improved soil & 51.7 & 42.2 & 39.4 & 38.7 \\
\hline \multirow{2}{*}{$\begin{array}{l}\text { Internal friction angle } \\
\text { degree }\end{array}$} & Untreated soil & 23.0 & 17.8 & 13.1 & 11.8 \\
\hline & Improved soil & 37.2 & 34.6 & 32.7 & 29.6 \\
\hline \multirow{2}{*}{$\begin{array}{l}\text { Decrease percentage of cohesion } \\
\%\end{array}$} & Untreated soil & - & 33.4 & 47.3 & 50.2 \\
\hline & Improved soil & - & 18.5 & 23.8 & 25.2 \\
\hline \multirow{2}{*}{$\begin{array}{l}\text { Decrease percentage of internal friction angle } \\
\%\end{array}$} & Untreated soil & - & 22.5 & 43.1 & 48.7 \\
\hline & Improved soil & - & 7.1 & 12.1 & 20.4 \\
\hline
\end{tabular}

TABLE 3: Results of CBR experiment.

\begin{tabular}{lccc}
\hline Sample state & Untreated soil & $\begin{array}{c}\text { Improved soil } \\
\text { (7 days) }\end{array}$ & $\begin{array}{c}\text { Improved soil } \\
(28 \text { days) }\end{array}$ \\
\hline CBR \% after 0 cycles & 6.1 & 18.3 & 19.3 \\
CBR \% after 3 cycles & 2.7 & 15.6 & 16.1 \\
Reduced percentage of CBR after 3 cycles \% & 55.7 & 14.8 & 16.6 \\
\hline
\end{tabular}

clay with $4 \%$ water glass solution and $0.4 \%$ aluminum sulfate is much higher than that of the untreated soil.

\section{Conclusions}

This paper uses laboratory experiments to investigate the feasibility of using water glass and aluminum sulfate to treat high liquid limit soil subgrade complications and discusses the liquid and plastic limits, maximum dry density, optimum moisture content, and water stability of the improved high liquid limit soil with water glass and aluminum sulfate. After observing the experimental results, the following conclusions were reached.

(1) With an increase in the mixing amount of water glass and aluminum sulfate, the liquid limit of the improved high liquid limit clay decreases, its plastic limit increases, and its plasticity index decreases. When the mixing amount of water glass solution with a concentration of $3.26 \mathrm{M}$ is $4 \%$ and the mixing amount of aluminum sulfate is $0.4 \%$, the liquid limit of the improved soil after being cured for seven days is $54.6 \%$ and its plasticity index is 21 , which meets the requirements for the plasticity index of subgrade filler as shown in the specifications for design of highway subgrades (JTG D30-2004).

(2) The maximum dry density of the improved high liquid limit soil with water glass and aluminum sulfate is lower than that of the untreated soil, while the optimum moisture content of the improved soil is greater.

(3) The gel generated during the reaction of water glass and aluminum sulfate is capable of prompting the soil grains to transform into aggregate. Therefore compared with that of the untreated soil, the clay content of the improved soil decreases, while the silt and coarse contents increase.

(4) The absolute and relative expansion rates of the improved soil are both lower than those of the untreated soil. The absolute expansion rate of the untreated and improved soils gradually increases with the increase in the number of dry and wet cycles, but the relative expansion rate first increases and then decreases.

(5) The cohesion and internal friction angle of the improved soil are both higher than those of the untreated soil; those of both the untreated and improved soils gradually decrease with the increase in the number of dry and wet cycles, but the rate of decrease gradually reduces with the increase in the number of dry and wet cycles; with the same number of dry and wet cycles, the decreased degree of cohesion of the improved soil is about one-half of that of the untreated soil, while the decreased degree of internal friction angle of improved soil is about onethird of that of the untreated soil.

(6) After three dry and wet cycles, the CBR of the untreated soil does not meet the requirements of the specifications. However, after being cured for seven days and being subjected to three dry and wet cycles, the CBR of the improved soil with $4 \%$ water glass solution and $0.4 \%$ aluminum sulfate solution meets the requirements of specifications; in addition, after three dry and wet cycles, the decreased degree of the CBR of the untreated soil is greater than that of the improved soil.

(7) The viscosity of the aluminum sulfate solution and water glass solution remains basically unchanged within a period of eight hours, and the two solutions do not coagulate during grouting construction; thus 
they are able to meet the requirements of grouting construction. In addition, the strength and water stability of the improved high liquid limit clay with water glass and aluminum sulfate increase significantly; thus it is shown that water glass and aluminum sulfate may be used to treat high liquid limit soil subgrade complications through grouting.

\section{Conflict of Interests}

The authors declare that there is no conflict of interests regarding the publication of this paper.

\section{Acknowledgment}

This work was supported by the Fundamental Research Funds for the Central Universities under Grants nos. 2009B13814 and 2014B04914.

\section{References}

[1] G. C. Qian and L. Y. Feng, "Test research on engineering behaviors of high liquid limit soil," China Journal of Highway and Transport, vol. 11, pp. 15-21, 1998.

[2] Z. Q. Luo, "Application of high liquid limit soil in freeway construction," Central South Highway Engineering, vol. 29, pp. 87-89, 2004.

[3] L. J. Wu, F. L. Zhong, C. X. Wu, and S. Yang, "Study on road made by high liquid limit soil," Chinese Journal of Geotechnical Engineering, vol. 25, pp. 193-195, 2003.

[4] Specifications for Design of Highway Subgrades, (JTG D302004), China Communications Press, Beijing, China, 2004.

[5] E. I. Stavridakis and T. N. Hatzigogos, "Influence of liquid limit and slaking on cement stabilized clayey admixtures," Geotechnical and Geological Engineering, vol. 17, no. 2, pp. 145154, 1999.

[6] G. Jegede, "Effect of soil properties on pavement failures along the F209 highway at Ado-Ekiti, south-western Nigeria," Construction and Building Materials, vol. 14, no. 6-7, pp. 311-315, 2000.

[7] Hohai University, Research Report of Inhomogeneous Deformation and Cracking Treatment Technology of Guangxi Highway Subgrade, Hohai University, 2011.

[8] B. Luo and X. Zhao, "Test study on improving high liquid limit red clay with crushed stone," Highway Engineering, vol. 34, pp. 131-134, 2009.

[9] F.-H. Li, "Experimental study of optimal proportion of gravel adopted to improve the properties of high liquid limit soil subgrade," Rock and Soil Mechanics, vol. 31, no. 3, pp. 785-788, 2010.

[10] E. A. Basha, R. Hashim, H. B. Mahmud, and A. S. Muntohar, "Stabilization of residual soil with rice husk ash and cement," Construction and Building Materials, vol. 19, no. 6, pp. 448-453, 2005.

[11] J. Zeng, Z.-B. Deng, X. Lan, and Q. Sheng, "Experimental study on properties of high liquid limit soil and red clay of Zhucheng Highway," Rock and Soil Mechanics, vol. 27, no. 1, pp. 89-92, 2006.
[12] N. Degirmenci, A. Okucu, and A. Turabi, "Application of phosphogypsum in soil stabilization," Building and Environment, vol. 42, no. 9, pp. 3393-3398, 2007.

[13] Y. Guney, D. Sari, M. Cetin, and M. Tuncan, "Impact of cyclic wetting-drying on swelling behavior of lime-stabilized soil," Building and Environment, vol. 42, no. 2, pp. 681-688, 2007.

[14] W.-H. Zhang, W.-Y. Xi, B.-T. Wang, and B.-N. Hong, "Test study of high liquid limit clay modified by quick lime used as sub-grade material," Journal of Central South University of Technology, vol. 15, no. 2, pp. 126-130, 2008.

[15] M. A. Sakr, M. A. Shahin, and Y. M. Metwally, "Utilization of lime for stabilizing soft clay soil of high organic content," Geotechnical and Geological Engineering, vol. 27, no. 1, pp. 105113, 2009.

[16] S. M. Rao, B. V. V. Reddy, and M. Muttharam, "The impact of cyclic wetting and drying on the swelling behaviour of stabilized expansive soils," Engineering Geology, vol. 60, no. 1-4, pp. 223233, 2001.

[17] A. Senol, T. B. Edil, M. S. Bin-Shafique, H. A. Acosta, and C. H. Benson, "Soft subgrades' stabilization by using various fly ashes," Resources, Conservation and Recycling, vol. 46, no. 4, pp. 365-376, 2006.

[18] G. B. Zhang and G. N. Yu, "Study on improvement of high liquid limit soil," Journal of Highway and Transportation Research and Development, vol. 22, pp. 71-74, 2005.

[19] S. Zeng, "Study of lab improvement test for high liquid limit clay," China and Overseas Highways, vol. 27, pp. 208-210, 2007.

[20] Test Methods of Soils for Highway Engineering (JTG E40-2007), China Communications Press, Beijing, China, 2007.

[21] H. W. Zheng, Study on the improvement and method for diseases control of high liquid limit soil subgrade [M.S. thesis], Hohai University, Nanjing, China, 2012. 

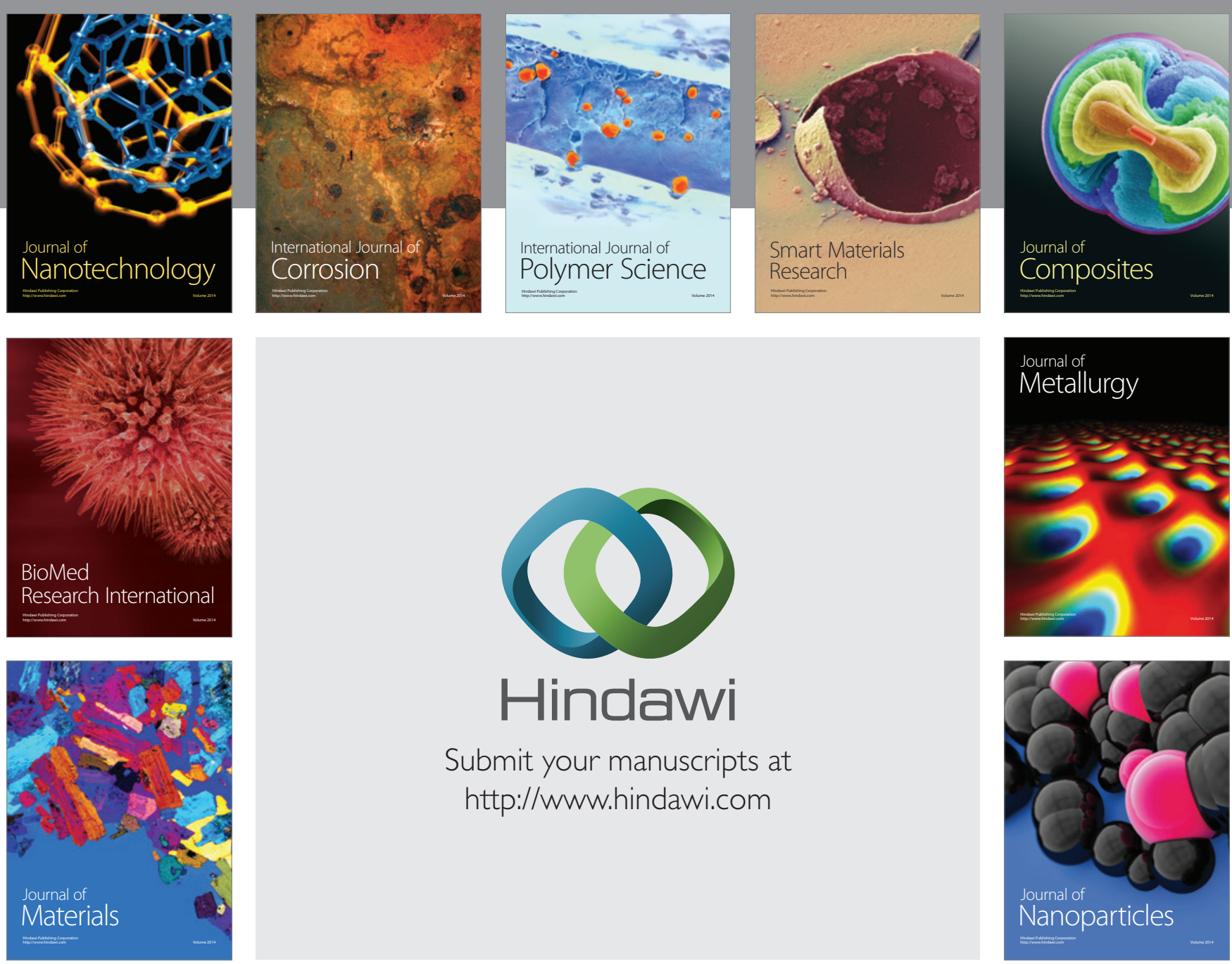

Submit your manuscripts at http://www.hindawi.com
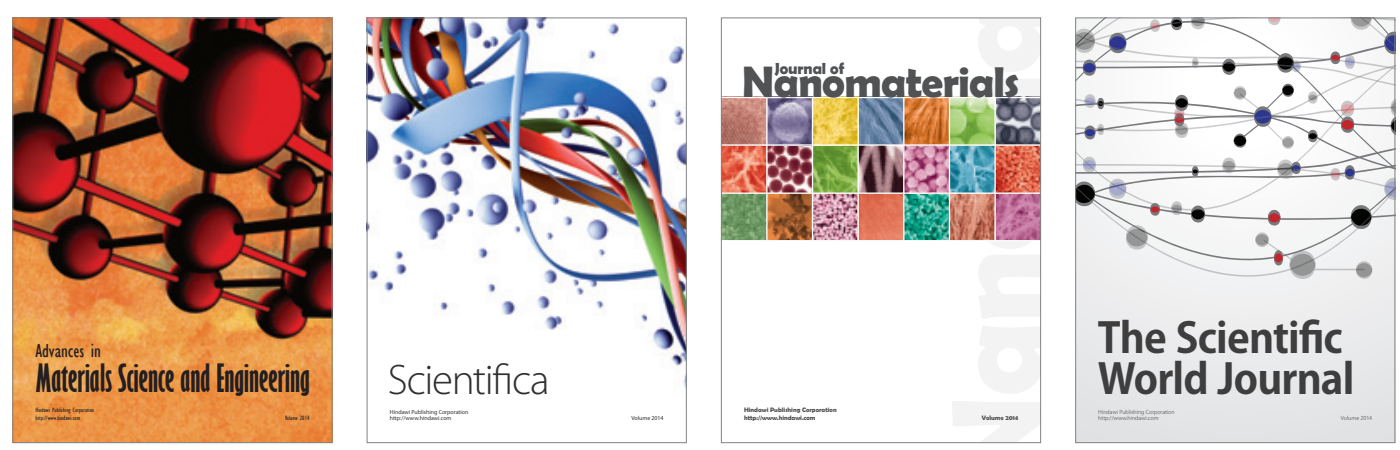

\section{The Scientific World Journal}
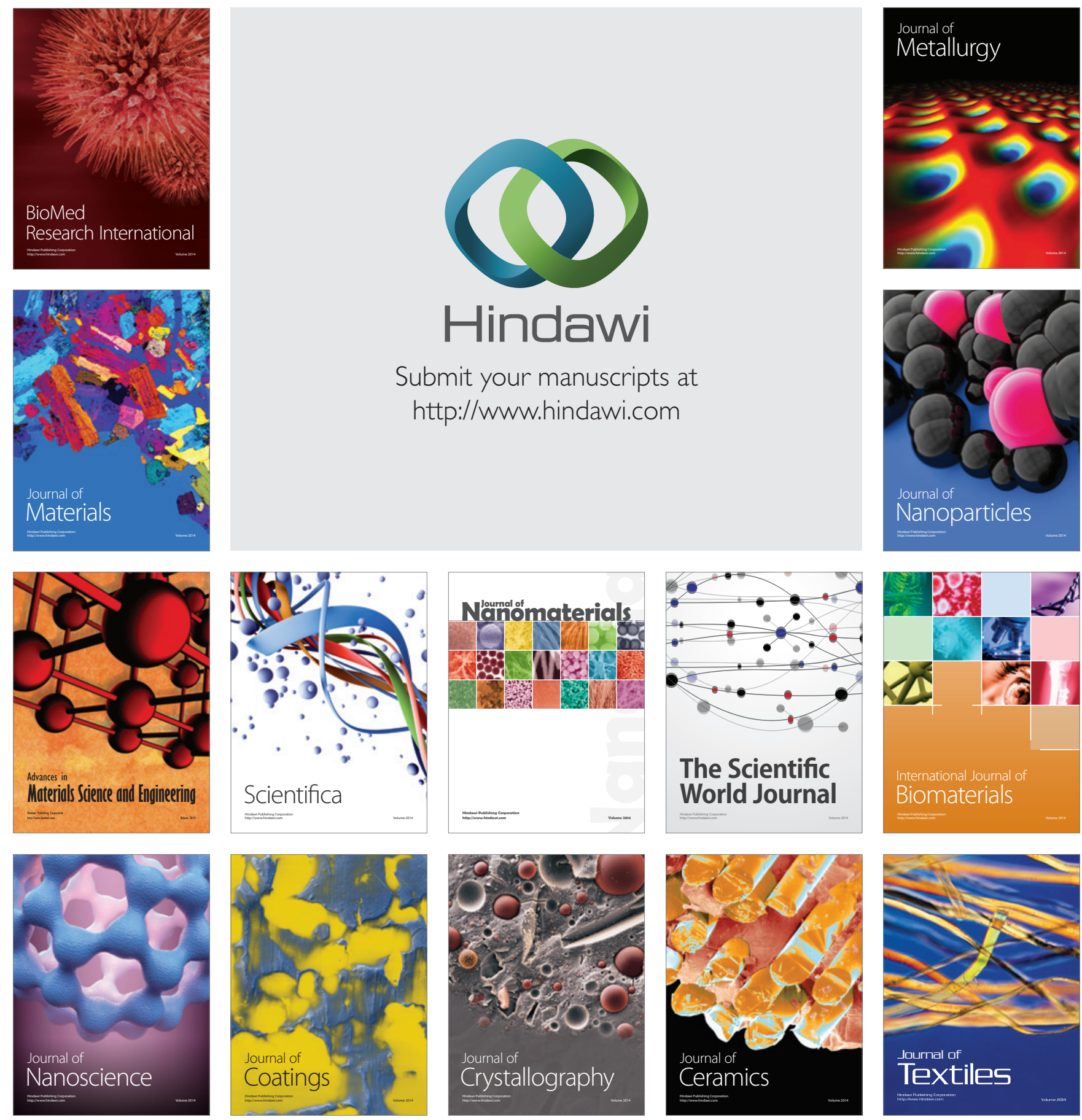